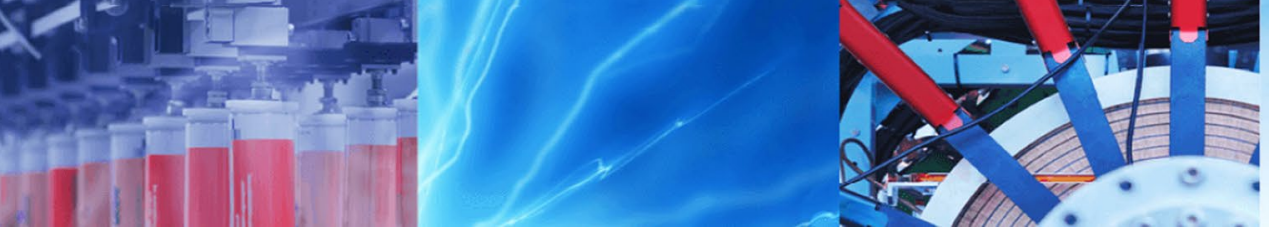

Research Article

\title{
Capillary electrophoresis-UV analysis using silica-layer coated capillary for separation of seven phenolic acids and caffeine and its application to tea analysis
}

\author{
Pattamaporn Hemwech ${ }^{1} \cdot$ Apinya Obma ${ }^{1} \cdot$ Sasinun Detsangiamsak ${ }^{1} \cdot$ Supa Wirasate $^{2} \cdot$ Pimchai Chaiyen $^{3}$. \\ Prapin Wilairat $^{4} \cdot$ Rattikan Chantiwas $^{1}$ (D)
}

Received: 20 August 2021 / Accepted: 27 October 2021

Published online: 17 November 2021

(C) The Author(s) 2021 OPEN

\begin{abstract}
This work presents an innovative silica-layer coated capillary with comparison study of the silica-layer coated capillary and the fused-silica capillary for the separation of seven phenolic acids viz. $p$-hydroxyphenylacetic acid (PHPA), $p$-coumaric acid (PCA), $p$-hydroxybenzoic acid (PHBA), caffeic acid (CFA), (3,4-dihydroxyphenyl)acetic acid (DHPA), gallic acid (GLA), and 2,3,4-trihydroxybenzoic acid (THBA), together with caffeine (CF), by capillary electro-chromatography (CEC) and micellar electrokinetic chromatography (MEKC), respectively. The running buffer was $25.0 \mathrm{mM}$ borate at pH 9.0, with addition of $50.0 \mathrm{mM}$ sodium dodecyl sulfate for the MEKC mode. The non-coated capillary could not separate all seven phenolic acids by CEC or MEKC. This was achieved using the coated capillary for both CEC and MEKC. The innovative coated capillary with CEC had plate number $N \geq 2.0 \times 10^{4} \mathrm{~m}^{-1}$ and resolution $R_{\mathrm{s}} \geq 1.6$ for all adjacent pairs of peaks. The capillary was also able to separate GLA and THBA which are structural isomers. Although MEKC mode provided comparable efficiency and selectivity, the reduced EOF of the coated capillary led to longer separation time. The linear calibration range of the seven phenolic acids and caffeine were different but the coefficients of determinations $\left(r^{2}\right)$ were all $>0.9965$. The precisions of the relative migration times and peak area ratios of analyte to internal standard were $0.1-1.8 \%$ and $1.8-6.8 \%$, respectively. There were no statistical differences in the efficiency of separation of the phenolic acids and caffeine for three coated capillaries. It was applied to the analysis of caffeine and phenolic acids in brewed tea using tyramine as the internal standard. The tea samples were diluted prior to analysis by CEC. The separation was less than 15 min. Caffeine, gallic acid and $p$-coumaric acid were detected and quantified. Caffeine and gallic acid contents were $10.8-15.0$ and $2.6-4.8 \mathrm{mg} \mathrm{g}^{-1}$ dry tea leaves, respectively. $p$-Coumaric acid was detected in only one of the samples with a content of $0.4 \mathrm{mg} \mathrm{g}^{-1}$. Percent recoveries of spiked diluted samples were $90 \pm 9$ to $106 \pm 13 \%$, respectively.
\end{abstract}

Supplementary Information The online version contains supplementary material available at https://doi.org/10.1007/s42452-02104849-1.

$\triangle$ Rattikan Chantiwas, rattikan.cha@mahidol.ac.th; rattikan.cha@mahidol.edu| ${ }^{1}$ Department of Chemistry and Center of Excellence for Innovation in Chemistry and Flow Innovation-Research for Science and Technology Laboratories (FIRST Labs), Faculty of Science, Mahidol University, Rama VI Rd., Bangkok 10400, Thailand. ${ }^{2}$ Department of Chemistry and Center for Surface Science and Engineering, Faculty of Science, Mahidol University, Salaya, Nakhorn Pathom 73170, Thailand. ${ }^{3}$ Department of Biomolecular Science and Engineering, School of Biomolecular Science and Engineering, Vidyasirimedhi Institute of Science and Technology (VISTEC), Wangchan Valley, Rayong 21210, Thailand. ${ }^{4}$ Analytical Sciences and National Doping Test Institute, Mahidol University, Rama VI Rd., Bangkok 10400, Thailand.

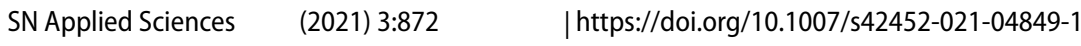




\section{Article highlights}

- Silica-layer coated capillary is first reported for simultaneous separation of seven phenolic acids by non-MEKC analysis.

- Performance between coated, and non-coated capillaries with analysis by CEC and MEKC were compared.

- Plate number, resolution, capillary reproducibility, and electroosmotic flow mobility are investigated.

\section{Graphical abstract}

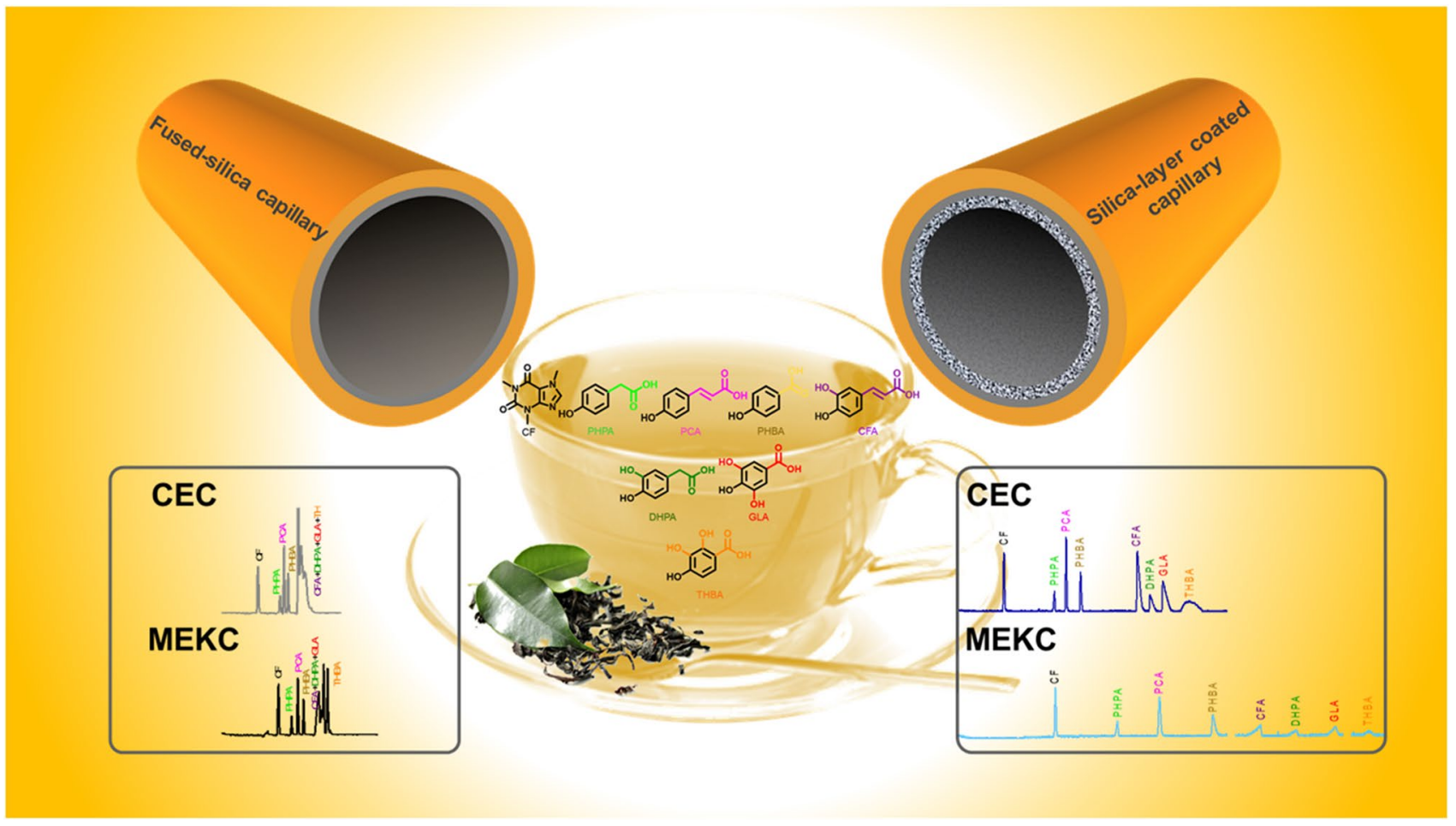

Keywords Caffeine $\cdot$ Capillary electrophoresis $\cdot$ Micellar electrokinetic chromatography $\cdot$ Phenolic acids $\cdot$ Silica coated capillary · Tea

\section{Abbreviations}

CEC Capillary electro-chromatography

CF Caffeine

CFA Caffeic acid

CMC Critical micelle concentration

CTAB Cetyltrimethyl ammonium bromide

DHPA (3,4-Dihydroxyphenyl)acetic acid

EOF Electroosmotic flow

GLA Gallic acid

HPLC High Performance Liquid Chromatography

LOD Limit of detection

MEKC Micellar electrokinetic chromatography

PCA $p$-Coumaric acid

PHBA $p$-Hydroxybenzoic acid

PHPA $p$-Hydroxyphenylacetic acid

RMT Relative migration time
RSD Relative standard deviation

SDS Sodium dodecyl sulfate

SEM Scanning electron microscopy

THBA 2,3,4-Trihydroxybenzoic acid

\section{Introduction}

Tea is a health-promoting drink as shown by nutrition research [1]. The chemical composition of tea depends on its production process. One type of compounds found in all tea is the flavanols which are antioxidants [2]. A typical serving of tea (250-300 mg dry tea leaves) contains $30-40 \% \mathrm{w} / \mathrm{w}$ catechin and 3-6\% w/w caffeine [3]. Caffeine is well known to help stimulate attention, and reduce fatigue [4]. Another class of compounds found in tea is 
the phenolic acids, such as gallic acid (GLA), p-coumaric acid (PCA), various derivatives of quinic acid, isomers of caffeoylquinic acid and caffeoyl glucose [5]. The main gallic ester component of tea, (-)-epigallocatechin gallate (EGCG) and its dimer, can decompose to gallic acid at high temperature during the manufacturing process and polymerize into pigments $[2,6]$. The latter influences the $\mathrm{pH}$ and color of tea $[7,8]$. Phenolic acids have health promoting properties, such as antioxidant, antimicrobial, anticancer, anti-inflammatory, and anti-mutagenic $[9,10]$.

Reports of HPLC-UV/DAD analysis of phenolic acids in tea are listed in Table S1 (Supplementary Information A). Sample extraction was either with hot water or alcohols [11-15]. Capillary electrophoresis with UV detection method (CE-UV) for analysis of phenolic acids and polyphenols are given in Table $1[8,16-20,29]$. Most studies employed micellar electrokinetic chromatography (MEKC) using borate buffer and sodium dodecyl sulfate (SDS) [16, $17,19,20]$. MEKC analysis with conventional non-coated capillary is the most common method for quantitative analysis of phenolic acids and polyphenol compounds. MEKC analysis employs surfactants to form micelles as a "pseudo-stationary phase" [21]. The concentration of the surfactant must be higher than its critical micellar concentration, which is ca. $8.2 \mathrm{mM}$ at $25^{\circ} \mathrm{C}$. However, too high surfactant concentration leads to large electrophoretic current that can cause Joule heating problem and increased viscosity of the running buffer [22-24]. The analytical features of the analysis of gallic acid and caffeine in fruit juices, wheat flour, and tomato samples including tea samples, viz. linear range, limit of detection (LOD), precision, recovery, and analysis time, are also listed in Table 1.

This work describes the first application of CEC with highly efficient innovative silica-layer coated capillary for the separation of seven phenolic acids viz. $p$-hydroxyphenylacetic acid (PHPA), $p$-coumaric acid (PCA), $p$-hydroxybenzoic acid (PHBA), caffeic acid (CFA), (3,4-dihydroxyphenyl)acetic acid (DHPA), gallic acid (GLA), and 2,3,4-trihydroxybenzoic acid (THBA), and caffeine (CF). The method, with tyramine as internal standard, is applied to the analysis of caffeine and the seven phenolic acids in brewed tea samples using direct injection into the capillary electrophoresis system. The developed method is validated in terms of linear calibration range, limit of detection, precision and recovery of spiked samples.

\section{Experimental}

\subsection{Chemicals}

Gallic acid (GLA, 3,4,5-trihydroxybenzoic acid), p-coumaric acid (PCA, (2E)-3-(4-hydroxyphenyl)acrylic acid), p-hydroxyphenylacetic acid (PHPA, (4-hydroxyphenyl)acetic acid), p-hydroxybenzoic acid (PHBA), 4-hydroxybenzoic acid), 2,3,4-trihydroxybenzoic acid (THBA), caffeine (CF, 1,3,7-trimethylpurine-2,6-dione) and tyramine, 4-(2-aminoethyl)phenol) were purchased from Sigma-Aldrich (St. Louis, MO, USA). (3,4-Dihydroxyphenyl)acetic acid (DHPA) and caffeic acid (CFA, (2E)-3-(3,4-dihydroxyphenyl)acrylic acid) were purchased from TCI (Portland, OR, USA). Sodium dodecyl sulfate (SDS) was from Alfa Aesar (Lancashire, UK). Methanol was purchased from Scharlau (Sentmenat, Spain). Boric acid was purchased from Merck (Darmstadt, Germany). Ultrapure water $(18.0 \mathrm{M} \Omega \cdot \mathrm{cm})$ was produced from Milli-Q Advantage A10 water purifying system (Merck, Darmstadt, Germany).

\subsection{Preparation of standard solutions and samples}

Stock $100.0 \mathrm{mM}$ standard solutions of individual phenolic acid, viz. PHPA, PHBA, GLA, DHPA, and THBA, were prepared in $1.00 \mathrm{~mL}$ of $\mathrm{MeOH}-\mathrm{H}_{2} \mathrm{O}(20: 80 \mathrm{v} / \mathrm{v})$, while $\mathrm{PCA}$ and CFA were prepared in $1.00 \mathrm{~mL}$ of $\mathrm{MeOH}-\mathrm{H}_{2} \mathrm{O}(40: 60$ $\mathrm{v} / \mathrm{v})$. Stock $100.0 \mathrm{mM}$ caffeine standard was prepared in $10.00 \mathrm{~mL}$ ultrapure water. The internal standard (IS) was $6.0 \mathrm{mM}$ tyramine in methanol. All stock solutions were stored at $4{ }^{\circ} \mathrm{C}$. For constructing the calibration plots working standard solutions were freshly prepared from the stock standards by diluting with the running buffer. The running buffer ( $25.0 \mathrm{mM}$ borate buffer, $\mathrm{pH} 9.0$ ) was prepared from boric acid and adjusting the $\mathrm{pH}$ to 9.0 with $0.1 \mathrm{M} \mathrm{NaOH}$. For MEKC, the borate buffer contained $50.0 \mathrm{mM}$ SDS.

Tea samples were purchased from local supermarkets in Bangkok, Thailand. An accurate weight of dry tea leaves is infused with $15.0 \mathrm{~mL}$ of water at $80^{\circ} \mathrm{C}$ for $10.0 \mathrm{~min}$. After cooling to room temperature, the solution is first filtered with Whatman no. 1 filter paper to remove the tea leaves, and then with a $0.45 \mu \mathrm{m}$ cellulose acetate syringe filter (Filtrex Technologies, Bangkok, Thailand). An aliquot of the clear filtrate is diluted with ultrapure water. A second aliquot of the diluted tea solution is further diluted with the running buffer and the internal standard added. The final dilution depends on the tea sample ( $\mathrm{T} 1, \mathrm{~T} 2$ or $\mathrm{T} 3)$ and the analyte to be quantified (caffeine, GLA or PCA). In all cases, the final solution for injection into the CEC-UV system contains the same concentration of the IS (i.e. $0.15 \mathrm{mM}$ tyramine), including the standard solutions of caffeine and phenolic acids employed for calibration.

\subsection{Capillary electrophoresis with UV detection}

The capillary electrophoresis instrument with a UV detector is an in-house assembled instrument (see picture of the system in Fig. S1 of Supplementary Information B). 


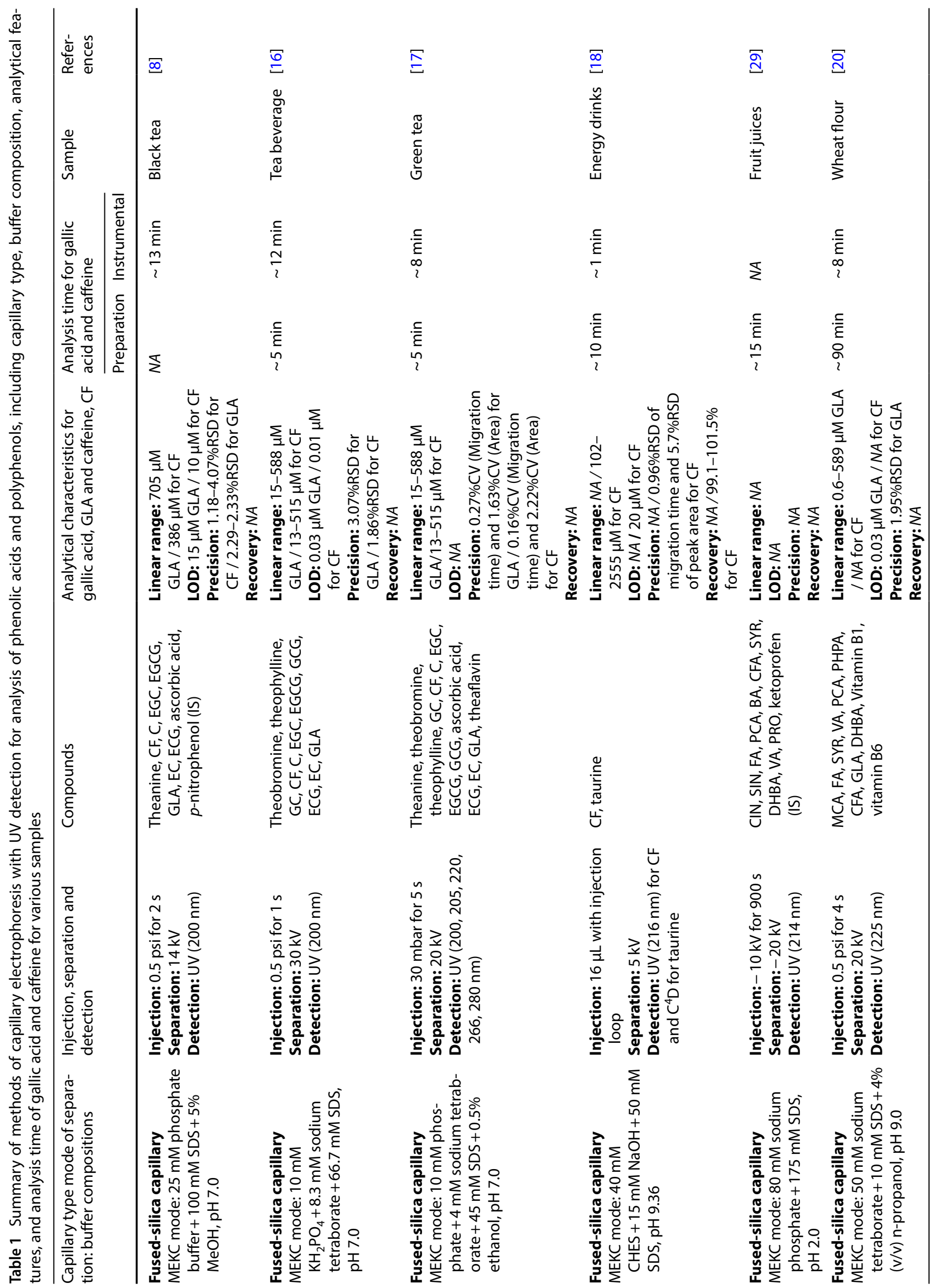




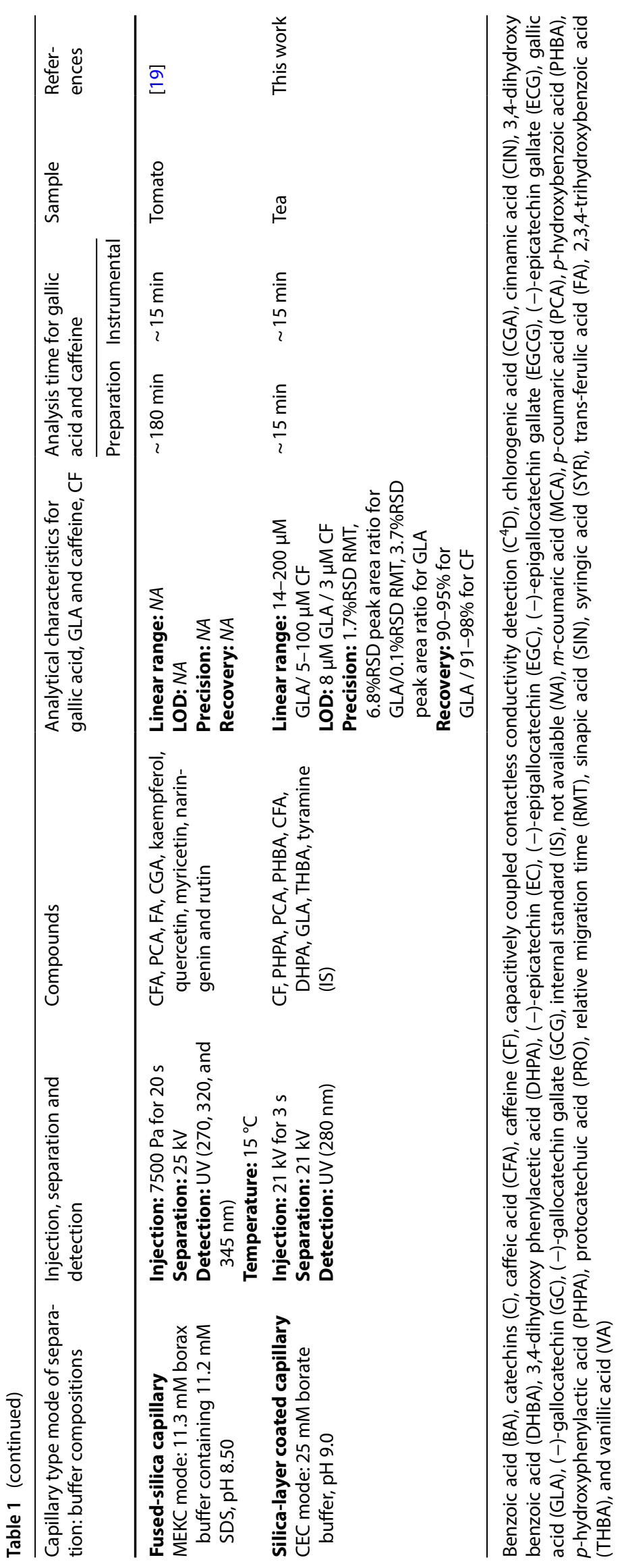


It consists of a UV detector (Applied Biosystem, 785A UV detector, CA, USA), a high voltage (HV) power supply (Spellman CZE1000R, Hauppauge, USA). The analog output from the detectors are recorded via a data acquisition system from eDAQ (Denistone East, NSW, Australia). The fused-silica capillaries (50 $\mu$ m i.d., $360 \mu$ m o.d.) are from Polymicro Technologies (Phoenix, AZ, USA). The capillary used for the electrophoresis is $60.0 \mathrm{~cm}$ long, with $38.0 \mathrm{~cm}$ effective length. The capillary is conditioned prior to use by rinsing with $0.1 \mathrm{M} \mathrm{NaOH}$, ultrapure water, and running buffer for 5, 10 and $5 \mathrm{~min}$, respectively, using a syringe pump (model CEC-MSP-001, Unimicro Technologies, CA, USA) connected to a $0.25-\mathrm{mm}$ i.d. Tygon ${ }^{\circledR}$ tubing (Tygon $\mathrm{S3}^{\mathrm{TM}}$, Cole-Parmer ${ }^{\oplus}$, IL, USA). The running buffer for CEC is $25.0 \mathrm{mM}$ borate buffer ( $\mathrm{pH} 9.0$ ) and with addition of $50.0 \mathrm{mM}$ SDS for MEKC. Electrokinetic injection is at $354 \mathrm{~V} \mathrm{~cm}^{-1}(21,000 \mathrm{~V})$ for $3 \mathrm{~s}$. The separation field strength is $354 \mathrm{~V} \mathrm{~cm}^{-1}(21,000 \mathrm{~V})$ and UV-absorbance detection is at $280 \mathrm{~nm}$.

\subsection{Preparation of silica-layer coated capillary by hydrothermal sol-gel process}

The process for coating the inner wall of the fused-silica capillary using a hydrothermal sol-gel method was previously developed by our group [25], based on previous reported methods [26-28]. The sol-gel mixture consists of cyclohexane $(3.00 \mathrm{~mL})$, TEOS $(500 \mu \mathrm{L})$, ultrapure water $(3.00 \mathrm{~mL})$, CTAB $(100 \mathrm{mg})$, urea $(60.0 \mathrm{mg}), 0.10 \mathrm{mM}$ acetic acid $(440 \mu \mathrm{L})$, and $n$-pentanol $(92 \mu \mathrm{L})$. The mixture is homogenized using an ultrasonic probe ( $2 \mathrm{kHz}, 20$ watts) for $30 \mathrm{~s}$. The sol-gel mixture is then immediately pumped into the capillary using a syringe pump at flow rate of 3.0

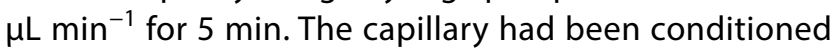
previously by flushing with $50 \% \mathrm{MeOH}, 1.0 \mathrm{M} \mathrm{NaOH}$ and ultrapure water, respectively. The ends of the capillary are then sealed with GC septa and the capillary heated in a gas chromatograph oven (HP 6890A, Agilent, Santa Clara, CA, USA) for $4 \mathrm{~h}$ at $70^{\circ} \mathrm{C}$. After cooling to room temperature, the capillary is rinsed with ethanol and ultrapure water and kept in an oven at $50{ }^{\circ} \mathrm{C}$ until required. Morphology of the inner wall of the coated capillary was observed by scanning electron microscopy (SEM). Figure S2(a)(iii) of Supplementary Information $C$ shows that a layer of uniform silica beads of $c a .100 \mathrm{~nm}$ thickness (see Fig. S2(a) (ii)) is deposited on the inner wall of the capillary [25]. The composition of deposited silica layer was characterized by FT-IR spectra. IR bands are observed at $786 \mathrm{~cm}^{-1}, 963 \mathrm{~cm}^{-1}$ and $1052 \mathrm{~cm}^{-1}$, which are characteristics of the $\mathrm{Si}-\mathrm{O}, \mathrm{Si}-$ $\mathrm{OH}$ and $\mathrm{Si}-\mathrm{O}-\mathrm{Si}$ bonds, respectively [25].

\section{Results and discussion}

\subsection{Comparison of separation performance of non-coated and innovative silica-layer coated capillaries using MEKC and CEC with UV detection}

\subsubsection{Separation mode}

Table 2 shows the chemical structures of the seven phenolic acids, caffeine and the tyramine (the internal standard) and their abbreviations. The compounds were employed in the study of their separation using CEC and MEKC employing conventional fused-silica capillary and the innovative silica-layer coated capillary, respectively. Running buffers were $25.0 \mathrm{mM}$ borate buffer $(\mathrm{pH} 9.0)$ for CEC with addition of $50.0 \mathrm{mM}$ SDS for MEKC.

The optimized concentration of $50.0 \mathrm{mM}$ SDS was employed for MEKC mode (see Fig. S3, Supplementary Information D). Figure 1 shows the electropherograms from this study. The CEC with non-coated capillary is able to separate only four compounds as shown in Fig. 1a (i), viz. PHPA (Peak 1), PCA (Peak 2), PHBA (Peak 3), and caffeine (Peak CF). The MEKC mode is more effective (see Fig. 1a (ii)) with separation of the phenolic acids, PHPA (Peak 1), PCA (Peak 2), and THBA (Peak 7). However, it was not able to separate CFA (Peak 4), DHPA (Peak 5), and GLA (Peak 6). Figure $1 \mathrm{~b}$ shows that the coated capillary gave baseline separation of all 8 compounds for both CEC and MEKC modes of separation. The separation of CFA, DHPA, GLA and THBA have not been previously reported using MEKC with conventional capillaries $[19,20,29]$. This is also the first report of the separation of the two isomers, GLA and THBA, which are structural isomers (see Table 2 for structures).

The coated capillary with MEKC has a much longer separation time due to partitioning of the compounds into the anionic micelles $[8,19]$. The CEC analysis has a total separation time of $15 \mathrm{~min}$, which is about 4 times faster than the MEKC separation. In addition, MEKC mode has a higher electrophoretic current than the CEC. The electrophoretic current of the MEKC is $18 \mu \mathrm{A}$ for both coated or non-coated capillaries, compared with $6 \mu \mathrm{A}$ for $\mathrm{CEC}$. Thus the CEC systems produce less Joule heating and lower band broadening.

\subsubsection{Separation efficiency}

Separation efficiency, expressed as plate number per effective capillary length $\left(\mathrm{m}^{-1}\right)$, was calculated by the equation $N=5.54 \times\left(t_{m} / W_{1 / 2}\right)^{2} \times\left(1 / I_{\text {eff }}\right)$, where $t_{m}$ is migration time $(\mathrm{s}), \mathrm{I}_{\text {eff }}$ is the effective length of the capillary $(\mathrm{m})$ and $\mathrm{W}_{1 / 2}$ 
is the peak width at half maximum height using the PowerChrom software (eDAQ, Denistone East, NSW, Australia). For the silica-layer coated capillary the efficiencies are in the range of $0.3-13 \times 10^{4} \mathrm{~m}^{-1}$ for both modes. Figure $2 \mathrm{a}$ shows the bar graphs of the efficiencies for the 7 phenolic acids. Measurements of the resolution $R_{\mathrm{s}}$ for all pairs of adjacent peaks in the four electropherograms in Fig. 1 are listed in Table S2 (Supplementary Information E). The $R_{\mathrm{s}}$ values for the silica-layer coated capillary are in the range of 1.6-22.0, respectively.

\subsubsection{Electroosmotic flow mobility}

The effect of the layer of silica coating on the electroosmotic flow was also studied. The EOF mobility was determined from conductivity measurements as described in a previous report [30]. The measured values of the EOF mobilities $\left(\mathrm{cm}^{2} \mathrm{~V}^{-1} \mathrm{~s}^{-1}\right)$ are given in Table 3. As expected, coating of the silica capillary decreased the EOF mobilities for both the CEC and MEKC modes. The EOF mobilities of coated capillary for different buffers, viz. $25.0 \mathrm{mM}$ phosphate buffer $\mathrm{pH} 2.70,25.0 \mathrm{mM}$ acetate buffer $\mathrm{pH}$ 4.00 and $25.0 \mathrm{mM}$ borate buffer $\mathrm{pH} 9.00$ are $0.78 \pm 0.08$, $2.57 \pm 0.07$ and $4.02 \pm 0.04 \times 10^{-4} \mathrm{~cm}^{2} \mathrm{~V}^{-1} \mathrm{~s}^{-1}$, respectively. The increase of mobility at the higher $\mathrm{pH}$ is as expected as more silanol groups on the surface of the silica wall are ionized.

The EOF mobilities for MEKC are always lower than for the CEC. The low EOF of the coated capillary for MEKC mode leads to longer migration times and band broadening of analytes with low net mobilities. More efficient dissipation of Joule heating is observed with a coated capillary, especially with MEKC, as it is more sensitive to temperature variation than the CEC mode [22]. The use of coated capillary is of benefit when using in-house CE system that has no temperature control.

\subsection{Analytical features of CEC-UV separation of phenolic acids and caffeine using the silica-layer coated capillary}

\subsubsection{Calibration}

Table 4 lists the linear ranges, calibration equations, coefficients of determination, instrumental LOD, precisions of relative migration time and peak area ratio (ratio of peak areas of analyte and internal standard in the same electropherogram) for the CEC-UV separation with the innovative silica-layer coated capillary [31]. Tyramine is used as the internal standard. The linear calibration range of the seven phenolic acids and caffeine have different ranges but the coefficients of determinations $\left(r^{2}\right)$ are $>0.9965$.

\subsubsection{Precision}

The precisions of relative migration times and peak area ratios are calculated from three replicate injections of a standard mixture containing $50 \mu \mathrm{M}$ caffeine, $100 \mu \mathrm{M}$ PHPA, $16 \mu \mathrm{M}$ PCA, $60 \mu \mathrm{M}$ PHBA, $50 \mu \mathrm{M}$ CFA, $40 \mu \mathrm{M}$ DHPA, $20 \mu \mathrm{M}$ $\mathrm{GLA}, 20 \mu \mathrm{M}$ THBA, and $0.15 \mathrm{mM}$ tyramine (IS). The precisions are $0.1-1.8 \% \mathrm{RSD}$ and $1.8-6.8 \% \mathrm{RSD}$, respectively.

\subsubsection{Limit of detection}

The instrumental limit of detection (LOD) is calculated from $3 \times$ (SD of regression)/(slope of regression) [32, 33]. The values are 1.8-19.4 $\mu \mathrm{M}$ for the acids and $3.4 \mu \mathrm{M}$ for caffeine.

\subsubsection{Reproducibility of capillary efficiency}

The values of plate number $N$ per one meter of effective capillary length of 3 different coated capillaries for separation of seven phenolic acids (see examples of electropherograms in Fig. S4 of Supplementary Information F), viz. PHPA, PCA, PHBA, CFA, DHPA, GLA, and THBA and caffeine are: $0.9-1.1 \times 10^{5} \mathrm{~m}^{-1}, 1.3-1.6 \times 10^{5} \mathrm{~m}^{-1}$, $1.3-1.4 \times 10^{5} \mathrm{~m}^{-1}, 5.8-6.9 \times 10^{4} \mathrm{~m}^{-1}, 5.0-6.9 \times 10^{4} \mathrm{~m}^{-1}$, $3.5-5.9 \times 10^{4} \mathrm{~m}^{-1}, 0.4-3.1 \times 10^{4} \mathrm{~m}^{-1}$, and $1.9-2.6 \times 10^{4} \mathrm{~m}^{-1}$, respectively (see Fig. 2b). The mean $N(n=3)$ of all seven phenolic acids and caffeine are $1.0 \times 10^{5} \mathrm{~m}^{-1}, 1.5 \times 10^{5} \mathrm{~m}^{-1}$, $1.3 \times 10^{5} \mathrm{~m}^{-1}, 6.5 \times 10^{4} \mathrm{~m}^{-1}, 6.2 \times 10^{4} \mathrm{~m}^{-1}, 4.6 \times 10^{4} \mathrm{~m}^{-1}$, $1.5 \times 10^{4}$, and $2.1 \times 10^{4} \mathrm{~m}^{-1}$, respectively. The values of $N$ of all seven phenolic acids and caffeine of the 3 capillaries tested lie within the range of mean $\pm 3 S D$, indicating that there is no statistical difference between the capillaries. Thus, the coating is highly uniform and reproducible for all the 3 capillaries.

\subsection{Analysis of tea samples by CEC-UV using innovative silica-layer coated capillary}

Samples of tea leaves were infused in hot water, cooled, filtered and diluted. The dilution factors of each tea sample are given in Table 5. These factors were obtained from prior experimental tests. Figure $3 a$ shows the electropherograms of diluted sample $\mathrm{T} 1$ for dilution factors of 10-, 20-, and 60-fold, respectively, and for the 60-fold dilution with spiked standard mixture (Fig. 3a (i), (ii), (iii) and (iv), respectively). Although salicylic acid is not a phenolic acid, it was added to assist the identification of peaks when there are multiple unknown peaks. The electropherogram of standard mixture is also given in Fig. 3a (v) for comparison. High dilution factors lead to reduction of matrix peaks and increased resolution of peaks. Dilution factors of 20- to 60-fold gave baseline separatuion of PCA 
Table 2 IUPAC names, common names (abbreviations) and chemical structures of the seven phenolic acids, caffeine and tyramine (internal standard)

\begin{tabular}{|c|c|c|}
\hline IUPAC name & Common name (abbreviation) & Structure \\
\hline 1,3,7-Trimethylpurine-2,6-dione & Caffeine (CF) & \\
\hline (4-Hydroxyphenyl)acetic acid & p-Hydroxyphenylacetic acid (PHPA) & \\
\hline (2E)-3-(4-Hydroxyphenyl)acrylic acid & $p$-Coumaric acid (PCA) & \\
\hline 4-Hydroxybenzoic acid & $p$-Hydroxybenzoic acid (PHBA) & \\
\hline (2E)-3-(3,4-Dihydroxyphenyl)acrylic acid & Caffeic acid (CFA) & \\
\hline (3,4-Dihydroxyphenyl)acetic acid & $-(\mathrm{DHPA})$ & \\
\hline 3,4,5-Trihydroxybenzoic acid & Gallic acid (GLA) & \\
\hline 2,3,4-Trihydroxybenzoic acid & $-($ THBA $)$ & \\
\hline 4-(2-Aminoethyl)phenol & Tyramine (IS) & \\
\hline
\end{tabular}

NOTE: GLA and THBA are structural isomers

and GLA, respectively, and factors of 60 - to 100 -fold for CF. Figure $3 \mathrm{~b}$ shows representative electropherograms of sample T1. Figure $3 \mathrm{~b}$ (i) is the electropherogram of the 40 -fold diluted tea sample and Fig. $3 \mathrm{~b}$ (ii) is of the same sample but spiked with PCA (at $5 \mu \mathrm{M}$ ) and GLA (at $10 \mu \mathrm{M}$ ), respectively. The quantitation of caffeine and phenolic acids in the three diluted tea samples are given in Table 5. Caffeine
(CF) and gallic acid (GLA) were detected in all samples, but $p$-coumaric acid (PCA) was found in only sample T1. The other 5 phenolic acids were not detected in all samples.

Percent recoveries of CF, PCA and GLA in diluted sample $\mathrm{T} 1$, and of $C F$ and GLA in diluted samples $T 2$ and $T 3$, were carried out. The percent recovery was calculated from $\%$ Recovery $=\left[\left(S_{1}-S_{2}\right) / S_{0}\right] \times 100$, where $S_{0}$ is the peak area 
(a) Non-coated capillary

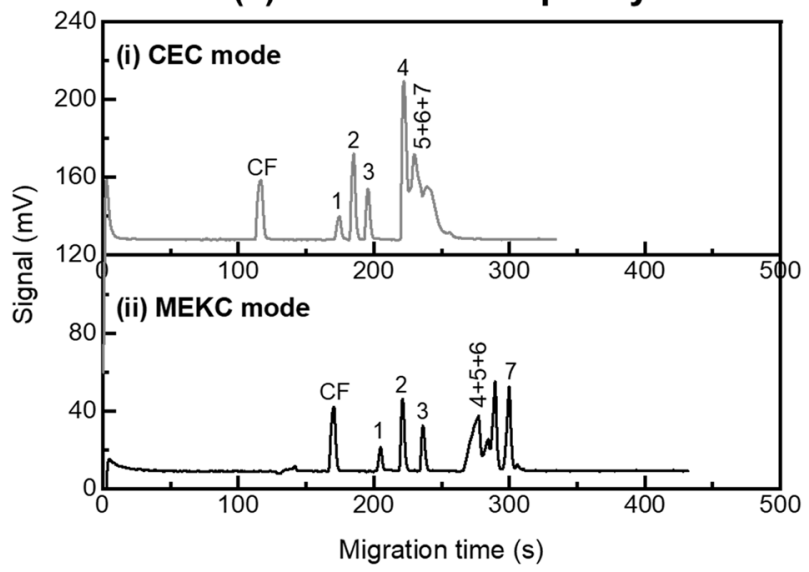

(b) Silica-layer coated capillary

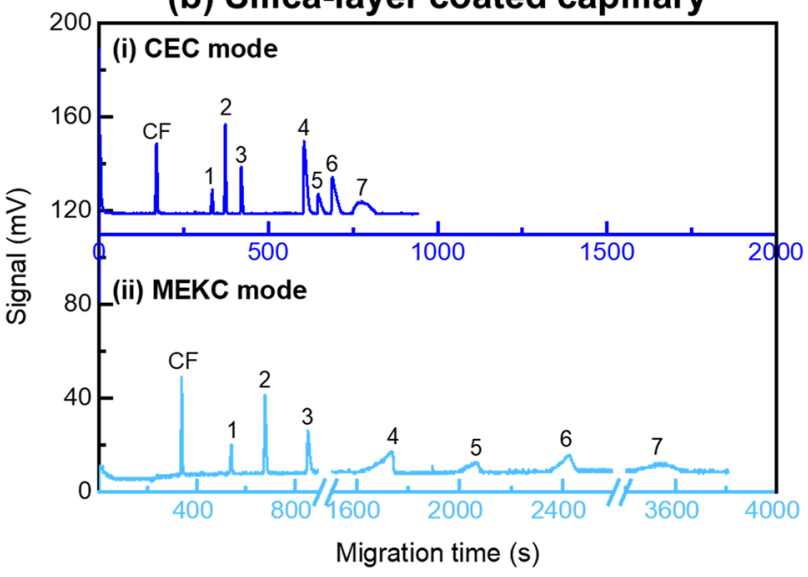

Fig. 1 Electropherograms of caffeine and seven standard phenolic acids using a fused-silica capillary and $\mathbf{b}$ silica-layer coated capillary. (i) CEC mode. (ii) MEKC mode. Sample: $100 \mu \mathrm{M}$ caffeine (Peak CF), $200 \mu$ M PHPA (Peak 1), $50 \mu$ M PCA (Peak 2), $100 \mu$ M PHBA (Peak 3), $200 \mu$ M CFA (Peak 4), $200 \mu$ M DHPA (Peak 5), $200 \mu M$ GLA (Peak 6), and $200 \mu \mathrm{M}$ THBA (Peak 7) (abbreviations as given in Table 2). The separation parameters are: running buffer: $25.0 \mathrm{mM}$ borate buffer ( $\mathrm{pH}$ 9.0) for CEC mode, addition of $50.0 \mathrm{mM}$ SDS for MEKC mode; electrokinetic injection: $21,000 \mathrm{~V}$ for $3 \mathrm{~s}$; field strength: 21,000 V; UV detection: $280 \mathrm{~nm}$

ratio of the standard solution, $\mathrm{S}_{1}$ is the peak area ratio of spiked diluted sample, and $\mathrm{S}_{2}$ is the peak area ratio of the non-spiked diluted sample. The percent recoveries are in the range of $90( \pm 9) \%$ to $106( \pm 13) \%(n=3)$. The small shift in migration times between non-spiked and spiked samples in Fig. 3a (iii) and (a) (iv) and also in Fig. 3b is due to the siphoning effect resulting from the imprecision in the placement of the buffer container inherent with the in-house capillary system.
The relative migration times (RMT) are shown in Table 5. The values are $1.29-1.38$ for caffeine, $4.62-8.80$ for GLA and 2.97 for PCA. The intra-day precisions are in the range of $0.36-4.12 \% R S D$. Using the dilution factor, the initial volume of the brew $(15.0 \mathrm{~mL})$ and the accurate weight of the samples of tea leaves (ca. $1.0 \mathrm{~g})$, the contents of caffeine (CF), gallic acid (GLA) and $p$-coumaric acid (PCA) can be calculated in unit of $\mathrm{mg} \mathrm{g}^{-1}$ tea leaves. The results are given in Table 5. Caffeine contents are 10.8 $\pm 0.5,15.0 \pm 1.1$ and $15.0 \pm 1.3 \mathrm{mg} \mathrm{g}^{-1}$, and the GLA contents are $2.6 \pm 0.1$, $3.9 \pm 0.1$, and $4.8 \pm 0.4 \mathrm{mg} \mathrm{g}^{-1}$, for samples $\mathrm{T} 1, \mathrm{~T} 2$ and $\mathrm{T} 3$, respectively. Sample $\mathrm{T} 1$ also has PCA at $0.35 \pm 0.04 \mathrm{mg} \mathrm{g}^{-1}$. The LOD of analysis are $1.0-1.8 \mathrm{mg} \mathrm{g}^{-1}$ for caffeine, $0.7-1.2 \mathrm{mg} \mathrm{g}^{-1}$ for GLA and $0.2 \mathrm{mg} \mathrm{g}^{-1}$ for PCA, respectively, depending on the dilution factor. The contents of caffeine and the two phenolic acids are similar to previous reports $[11,12,14,15,17]$.

This method, with tyramine as internal standard, is the first application of coated capillary with CEC for the analysis of caffeine and phenolic acids in tea samples. The separation time is $15 \mathrm{~min}$ with only dilution prior to direct injection into the capillary electrophoresis system. Table 1 lists the application of MEKC-UV for analysis of phenolic acids and polyphenols. Most of the reports employ conventional non-coated capillary. MEKC has limitation when using SDS concentrations very much above the CMC due to the Joule heating effect. This is of particular problem for in-house assembled capillary electrophoresis with no efficient temperature control.

\section{Conclusions}

An innovative silica coated capillary was successful in separating seven phenolic acids and caffeine using CEC. Previous methods employed the MEKC mode with conventional non-coated capillary (see Table 1). The running electrolyte in this work was boric acid at $\mathrm{pH} 9.0$ and detection was UV absorbance at $280 \mathrm{~nm}$. The coated capillary has a lower EOF mobility than the non-coated capillary but still has a total separation time of $15 \mathrm{~min}$. The modified capillary has a plate number $N \geq 2.0 \times 10^{4} \mathrm{~m}^{-1}$ and peak resolution $R_{\mathrm{s}} \geq 1.6$ for all adjacent pairs of peaks of the 8 compounds. The plate numbers of all analytes measured using three silica coated capillaries lay within mean \pm 3 SD. The linear calibration range of the seven phenolic acids are different but span 2-250 $\mu \mathrm{M}$. The coefficients of determination $\left(r^{2}\right)$ for the acids are $>0.9965$, with instrumental LOD in 
Fig. 2 Bar graphs of a plate number $N$ per one meter of effective capillary length of the silica-layer coated capillary for CEC (dark blue) and MEKC (light blue) calculated using the peak widths of caffeine (CF) and 7 phenolic acids (PHPA, PCA, PHBA, CFA, DHPA, GLA, and THBA). b Bar graphs of plate number $N$ per meter of the 7 phenolic acids and caffeine (CF) for three different coated capillaries. Concentrations of the compounds are: $100 \mu \mathrm{M}$ caffeine (CF), $200 \mu \mathrm{M}$ PHPA, $50 \mu \mathrm{M}$ PCA, $100 \mu \mathrm{M}$ PHBA, $200 \mu \mathrm{M}$ CFA, $200 \mu \mathrm{M}$ DHPA, $200 \mu \mathrm{M}$ GLA, $200 \mu \mathrm{M}$ THBA. The separation parameters are: running buffer: $25.0 \mathrm{mM}$ borate buffer $(\mathrm{pH}$ 9.0); electrokinetic injection: $21,000 \mathrm{~V}$ for $3 \mathrm{~s}$; field strength: 21,000 V; UV detection: $280 \mathrm{~nm}$. Data are mean \pm SD $(n=3)$. See Table 2 for abbreviations of the phenolic acids

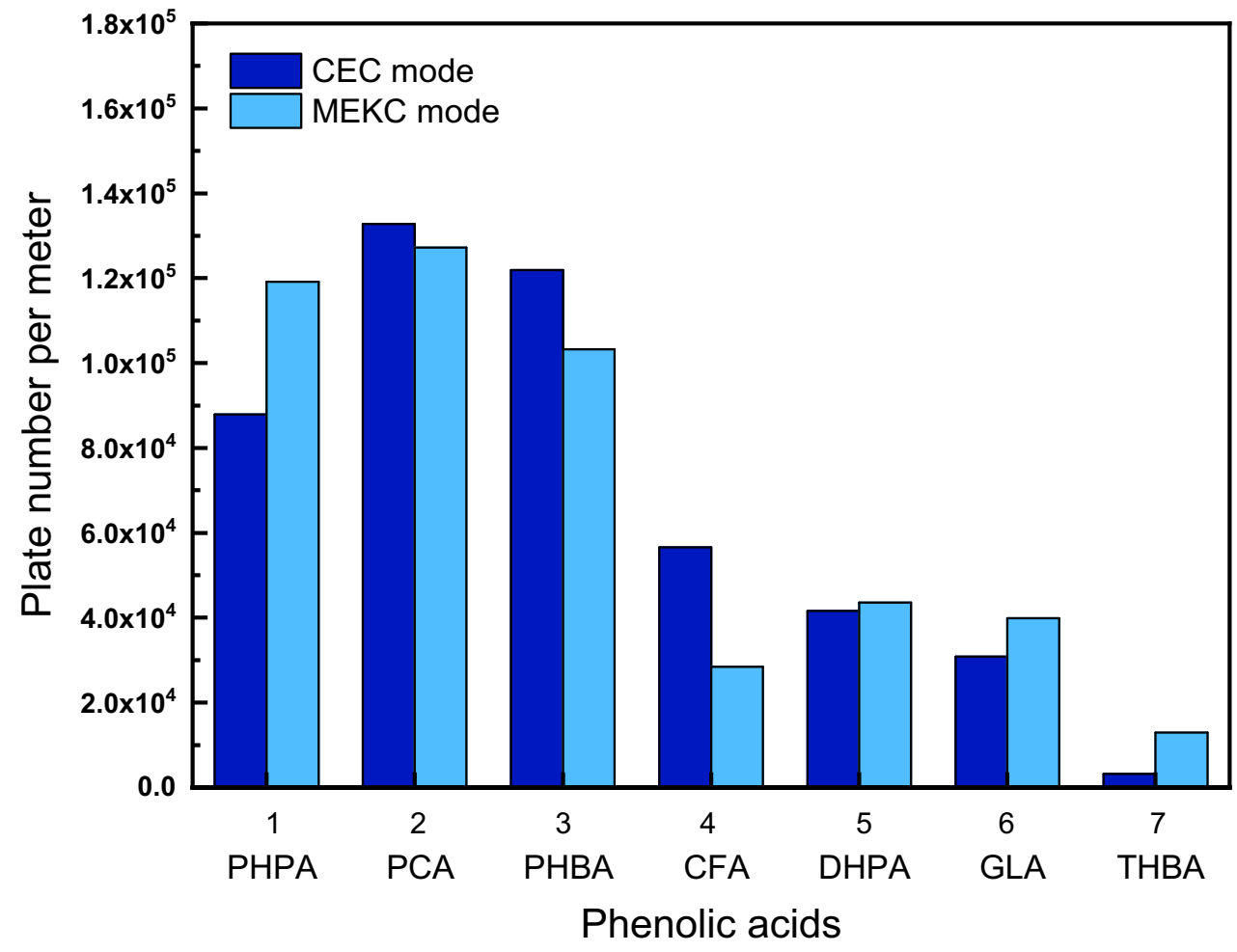

(b)

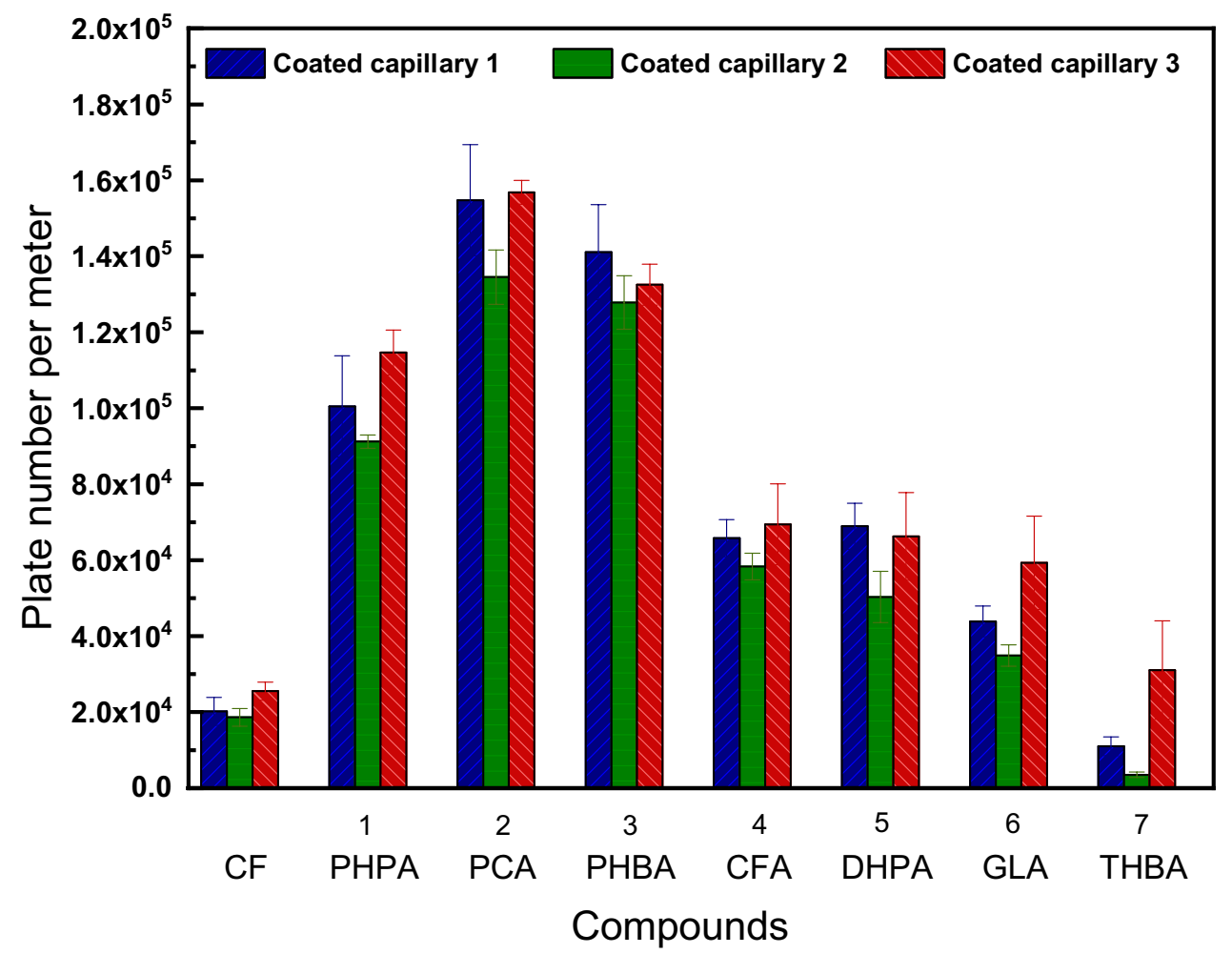


Table 3 EOF mobilities from using four separation systems: silicalayer coated capillary-CEC mode, silica-layer coated capillary-MEKC mode, fused-silica capillary-CEC mode, and fused-silica capillaryMEKC mode

\begin{tabular}{ll}
\hline Capillary type and separation mode & $\begin{array}{l}\mathrm{EOF} \pm \mathrm{SD}\left(\times 10^{-4}\right) \\
(\% \mathrm{RSD}) \mathrm{Cm}^{2} \mathrm{~V}^{-1} \mathrm{~s}^{-1}, \\
n=3\end{array}$ \\
\hline $\begin{array}{l}\text { Silica-layer coated capillary } \\
\text { CEC mode }\end{array}$ & $2.84 \pm 0.13(4.6)$ \\
MEKC mode & $1.46 \pm 0.12(7.9)$ \\
Fused-silica capillary & \\
CEC mode & $5.65 \pm 0.06(1.1)$ \\
MEKC mode & $4.26 \pm 0.04(0.9)$ \\
\hline
\end{tabular}

the range of 1.8-19.4 $\mu \mathrm{M}$. Caffeine has a linear calibration range of $5-100 \mu \mathrm{M}\left(r^{2}>0.9994\right)$, with instrumental LOD of $3.4 \mu \mathrm{M}$.

The system was applied to the analysis of caffeine and phenolic acids in infused tea samples prepared with hot water. After cooling, filtering and serial dilution with ultrapure water and running buffer, the samples were analyzed using electrokinetic injection. Caffeine and gallic acid were detected and quantified in all three samples, using tyramine as the internal standard. $p$-Coumaric acid was also detected in one sample. The method is convenient, rapid with separation time of only $15 \mathrm{~min}$ and has

Table 4 Validation data for CEC separation of phenolic acids and caffeine using silica-layer coated capillary and UV detection

\begin{tabular}{|c|c|c|c|c|}
\hline \multirow[t]{2}{*}{ Compound } & \multirow[t]{2}{*}{ Linear range $(\mu \mathrm{M})$; regression equation $\pm S D, r^{2}$} & \multirow[t]{2}{*}{$\operatorname{LOD}^{\mathrm{a}}(\mu \mathrm{M})$} & \multicolumn{2}{|c|}{ Precision (\%RSD) $(n=3)$} \\
\hline & & & $\begin{array}{l}\text { Relative migration } \\
\text { time }\end{array}$ & Peak area ratio \\
\hline Caffeine & $5-100 ; y=(0.0547 \pm 0.0009) x-(0.14 \pm 0.05), 0.9994$ & 3.4 & 0.1 & 3.7 \\
\hline PHPA & $15-200 ; y=(0.0073 \pm 0.0001) x+(0.07 \pm 0.01), 0.9993$ & 6.3 & 0.7 & 4.9 \\
\hline PCA & $2-65 ; y=(0.092 \pm 0.001) x-(0.02 \pm 0.04), 0.9992$ & 1.8 & 0.6 & 1.8 \\
\hline PHBA & $8-250 ; y=(0.0213 \pm 0.0002) x-(0.00 \pm 0.02), 0.9972$ & 4.0 & 0.7 & 4.9 \\
\hline CFA & $25-150 ; y=(0.041 \pm 0.003) x-(0.7 \pm 0.3), 0.9881$ & 19.4 & 1.5 & 6.0 \\
\hline DHPA & $20-160 ; y=(0.0168 \pm 0.0007) x+(0.04 \pm 0.07), 0.9965$ & 11.7 & 1.6 & 5.7 \\
\hline GLA & $14-200 ; y=(0.0404 \pm 0.0008) x+(0.01 \pm 0.08), 0.9984$ & 7.9 & 1.7 & 6.8 \\
\hline THBA & $14-200 ; y=(0.0425 \pm 0.0007) x-(0.08 \pm 0.08), 0.9988$ & 7.0 & 1.8 & 3.7 \\
\hline
\end{tabular}

${ }^{\mathrm{a}} \mathrm{LOD}$ calculated from $3 \times(\mathrm{SD}$ of regression)/(slope of regression)

Table 5 Results of CEC-UV analysis using silica-layer coated capillary of caffeine and phenolic acids in diluted brewed tea samples (T1, T2 and T3), together with the calculated contents in $\mathrm{mg} \mathrm{g}^{-1}$ and percent recovery of spiked diluted samples

\begin{tabular}{|c|c|c|c|c|c|c|c|c|c|}
\hline \multirow[t]{2}{*}{ Sample } & \multirow{2}{*}{$\begin{array}{l}\text { Detected } \\
\text { com- } \\
\text { pound }\end{array}$} & \multicolumn{2}{|c|}{$\begin{array}{l}\text { Relative migration time } \\
\text { (RMT) }^{\mathrm{a}}\end{array}$} & \multirow[t]{2}{*}{ Dilution factor } & \multicolumn{3}{|c|}{$\begin{array}{l}\text { Measured concentration } \pm S D(n=3) \\
(\mu M)\end{array}$} & \multirow{2}{*}{$\begin{array}{l}\text { Percent recov- } \\
\text { ery } \pm \text { SD }(\%) \\
(\% \text { RSD) }\end{array}$} & \multirow{2}{*}{$\begin{array}{l}\text { Calculated con- } \\
\text { tent } \pm \mathrm{SD}(n=3) \\
\left(\mathrm{mg} \mathrm{g}^{-1}\right)^{\mathrm{c}}\end{array}$} \\
\hline & & $\mathrm{RMT} \pm \mathrm{SD}(n=3)$ & $\%$ RSD & & $\begin{array}{l}\text { Amount in } \\
\text { non-spiked } \\
\text { sample }^{b}\end{array}$ & $\begin{array}{l}\text { Spiked } \\
\text { stand- } \\
\text { ard }\end{array}$ & $\begin{array}{l}\text { Amount } \\
\text { in spiked } \\
\text { sample }\end{array}$ & & \\
\hline \multirow[t]{3}{*}{$\mathrm{T} 1$} & CF & $1.29 \pm 0.00$ & 0.36 & 100-fold & $37 \pm 2$ & 10 & $47 \pm 1$ & $90 \pm 10(13)$ & $10.8 \pm 0.5$ \\
\hline & PCA & $2.97 \pm 0.00$ & 1.27 & 40-fold & $4 \pm 0$ & 5 & $9 \pm 1$ & $110 \pm 10(12)$ & $0.35 \pm 0.04$ \\
\hline & GLA & $7.40 \pm 0.23$ & 3.10 & 40-fold & $26 \pm 1$ & 10 & $35 \pm 1$ & $90 \pm 9(10)$ & $2.6 \pm 0.1$ \\
\hline \multirow[t]{2}{*}{$\mathrm{T} 2$} & $\mathrm{CF}$ & $1.38 \pm 0.01$ & 0.66 & 150-fold & $29 \pm 2$ & 10 & $38 \pm 1$ & $95 \pm 10(10)$ & $15.0 \pm 1.1$ \\
\hline & GLA & $4.62 \pm 0.19$ & 4.12 & 40-fold & $30 \pm 1$ & 10 & $39 \pm 1$ & $90 \pm 6(6)$ & $3.9 \pm 0.1$ \\
\hline \multirow[t]{2}{*}{ T3 } & $\mathrm{CF}$ & $1.36 \pm 0.01$ & 0.41 & 150-fold & $32 \pm 3$ & 10 & $42 \pm 1$ & $100 \pm 10(10)$ & $15.0 \pm 1.3$ \\
\hline & GLA & $8.80 \pm 0.07$ & 0.81 & 60-fold & $29 \pm 3$ & 10 & $39 \pm 1$ & $100 \pm 9(11)$ & $4.8 \pm 0.4$ \\
\hline
\end{tabular}

a Relative migration time (RMT): ratio of migration time of compound to migration time of internal standard (0.15 mM tyramine)

${ }^{\mathrm{b}}$ Instrumental LODs of $6 \mu \mathrm{M}$ for PHPA, $2 \mu \mathrm{M}$ for PCA, $4 \mu \mathrm{M}$ for PHBA, $19 \mu \mathrm{M}$ for CFA, $12 \mu \mathrm{M}$ for DHPA, and $7 \mu \mathrm{M}$ for THBA

${ }^{C}$ Not Detected ( $<$ LOD of analysis; 0.2 and $0.3 \mathrm{mg} \mathrm{PCA} \mathrm{g}^{-1}$ dry weight of tea leaves for $\mathrm{T} 2$ and $\mathrm{T} 3$, respectively) 
Fig. 3 a Electropherograms for different dilution factors of sample T1. (i) Tenfold dilution, (ii) 20 -fold dilution, (iii) 60-fold dilution, (iv) 60-fold dilution spiked with $50 \mu \mathrm{M}$ PHPA, 3.5 $\mu \mathrm{M}$ PCA, $15 \mu \mathrm{M}$ PHBA, $50 \mu \mathrm{M}$ salicylic acid (SA), $12.5 \mu \mathrm{M}$ CFA, $50 \mu \mathrm{M}$ DHPA, $45 \mu \mathrm{M} \mathrm{GLA}$, and $60 \mu \mathrm{M}$ THBA and (v) mixture of standard phenolic acids and caffeine at $25 \mu \mathrm{M}$ caffeine (CF), $100 \mu \mathrm{M}$ PHPA, $7 \mu \mathrm{M}$ PCA, $30 \mu \mathrm{M}$ PHBA, $170 \mu \mathrm{M}$ SA, $25 \mu \mathrm{M}$ CFA, $100 \mu \mathrm{M}$ DHPA, $90 \mu \mathrm{M}$ GLA, and $120 \mu \mathrm{M}$ THBA. See peak identifications are as shown in Fig. $1, *$ : unidentified peak. b Electropherograms of 40 -fold diluted tea sample T1: non-spiked (red) and spiked (blue) with $10 \mu \mathrm{M}$ caffeine (CF), $5 \mu \mathrm{M}$ PCA (peak 2) and $10 \mu \mathrm{M} \mathrm{GLA} \mathrm{(peak}$ 6), respectively. Inset is the expanded views of PCA and GLA peaks. Peak identification: IS: tyramine; CF: caffeine; peak 2: PCA; peak 6: GLA; $*$ : unidentified peak (a)

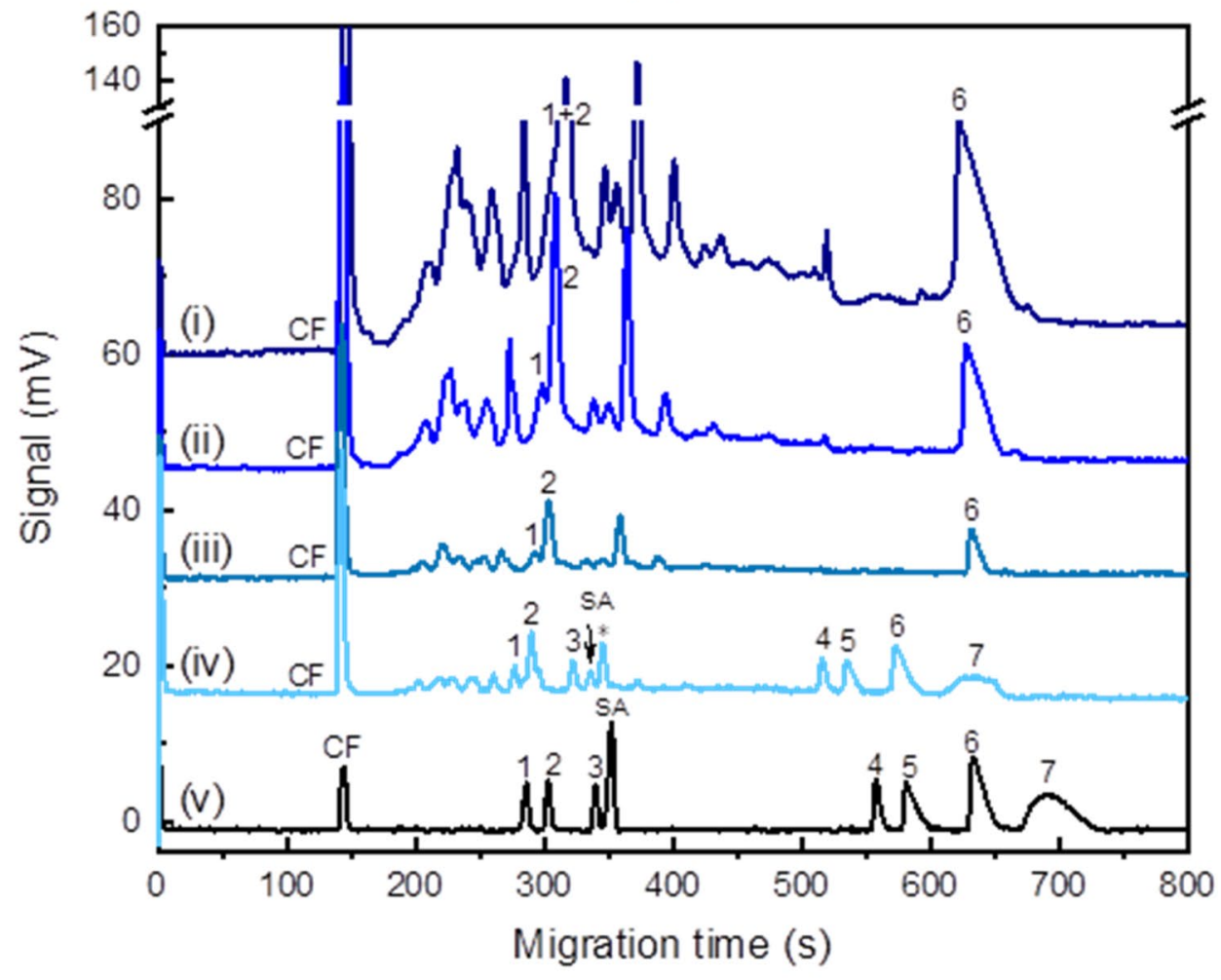

(b)

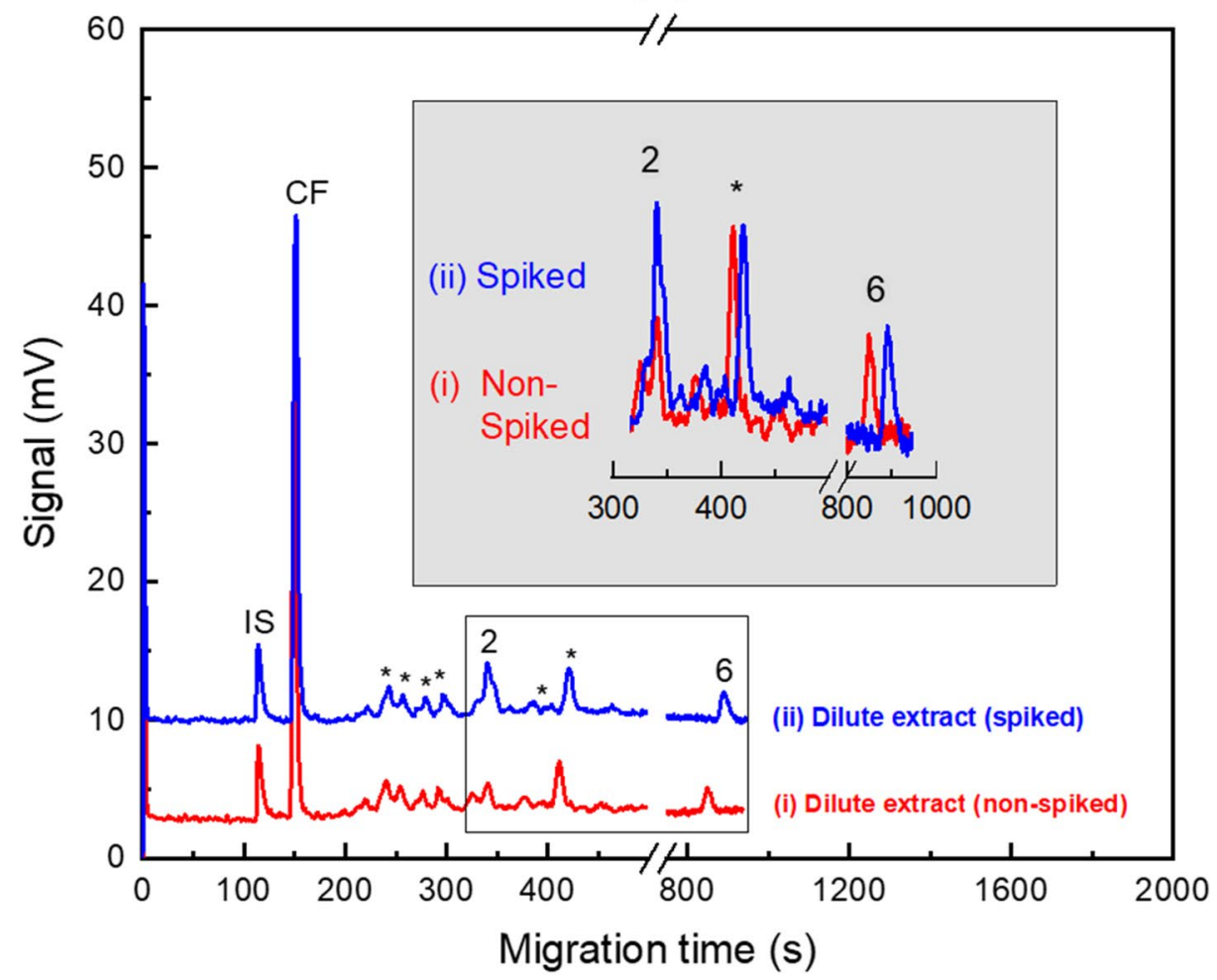


potential for convenient determination of phenolic acids and caffeine content for assessment of tea quality.

Acknowledgements This work is funded by National Research Council of Thailand (NRCT): NRCT5-RSA63015-18. Thanks to Faculty of Science, Mahidol University. The Science Achievement Scholarship of Thailand (SAST) is gratefully acknowledged for scholarships to $\mathrm{PH}$, and AO. The Center of Excellence for Innovation in Chemistry (PERCH$\mathrm{CIC})$, Ministry of Higher Education, Science, Research and Innovation, and International Research Network (IRN/502/2563) are gratefully acknowledged for support.

Author contributions $\mathrm{PH}$ : Investigation, Methodology, Validation, Visualization, Writing-original draft. AO: Methodology, Writing of sections. SD: Investigation. SW: Advise. PC: Funding acquisition, Resource. PW: Supervision, Review and Editing. RC: Conceptualization, Data curation, Funding acquisition, Project administration, Writing-Review, Editing, Supervision.

\section{Declarations}

\section{Conflict of interest There are no conflicts to declare.}

Human and animal rights This article does not contain any studies with human participants or animals performed by any of the authors.

Informed consent Not applicable.

Open Access This article is licensed under a Creative Commons Attribution 4.0 International License, which permits use, sharing, adaptation, distribution and reproduction in any medium or format, as long as you give appropriate credit to the original author(s) and the source, provide a link to the Creative Commons licence, and indicate if changes were made. The images or other third party material in this article are included in the article's Creative Commons licence, unless indicated otherwise in a credit line to the material. If material is not included in the article's Creative Commons licence and your intended use is not permitted by statutory regulation or exceeds the permitted use, you will need to obtain permission directly from the copyright holder. To view a copy of this licence, visit http://creativecommons. org/licenses/by/4.0/.

\section{References}

1. Khan N, Mukhtar H (2013) Tea and health: studies in humans. Curr Pharm Des 19:6141-6147. https://doi.org/10.2174/13816 12811319340008

2. Du G-J, Zhang Z, Wen X-D, Yu C, Calway T, Yuan C-S et al (2012) Epigallocatechin Gallate (EGCG) is the most effective cancer chemopreventive polyphenol in green tea. Nutrients 4:16791691. https://doi.org/10.3390/nu4111679

3. Mukhtar H, Ahmad N (1999) Cancer chemoprevention: future holds in multiple agents. Toxicol Appl Pharmacol 158:207-210. https://doi.org/10.1006/taap.1999.8721

4. Camandola S, Plick N, Mattson MP (2019) Impact of coffee and cacao purine metabolites on neuroplasticity and neurodegenerative disease. Neurochem Res 44:214-227. https://doi.org/10. 1007/s11064-018-2492-0

5. Lorenzo JM, Munekata PES (2016) Phenolic compounds of green tea: Health benefits and technological application in food. Asian
Pac J Trop Biomed 6:709-719. https://doi.org/10.1016/j.apjtb. 2016.06.010

6. Zhou J, Wu Y, Long P, Ho C-T, Wang Y, Kan Z et al (2019) LC-MSbased metabolomics reveals the chemical changes of polyphenols during high-temperature roasting of large-leaf yellow tea. J Agric Food Chem 67:5405-5412. https://doi.org/10.1021/acs. jafc.8b05062

7. Obanda M, Owuor PO, Taylor SJ (1997) Flavanol composition and caffeine content of green leaf as quality potential indicators of kenyan black teas. J Sci Food Agric 74:209-215. https://doi.org/ 10.1002/(SICI)1097-0010(199706)74:2\%3C209::AID-JSFA789\% 3E3.0.CO;2-4

8. Aucamp JP, Hara Y, Apostolides $Z$ (2000) Simultaneous analysis of tea catechins, caffeine, gallic acid, theanine and ascorbic acid by micellar electrokinetic capillary chromatography. J Chromatogr A 876:235-242. https://doi.org/10.1016/s0021-9673(00) 00145-x

9. Kumar N, Goel N (2019) Phenolic acids: natural versatile molecules with promising therapeutic applications. Biotechnol Rep 24:e00370. https://doi.org/10.1016/j.btre.2019.e00370

10. Hayat $\mathrm{K}$, Iqbal H, Malik U, Bilal U, Mushtaq S (2015) Tea and its consumption: benefits and risks. Crit Rev Food Sci Nutr 55:939954. https://doi.org/10.1080/10408398.2012.678949

11. Zuo $Y$, Chen H, Deng $Y$ (2002) Simultaneous determination of catechins, caffeine and gallic acids in green, Oolong, black and pu-erh teas using HPLC with a photodiode array detector. Talanta 57:307-316. https://doi.org/10.1016/S0039-9140(02) 00030-9

12. Fernández PL, López A, Pablos F, González AG, Martín MJ (2003) The use of catechins and purine alkaloids as descriptors for the differentiation of tea beverages. Microchim Acta 142:79-84. https://doi.org/10.1007/s00604-003-0002-8

13. Peng L, Song X, Shi X, Li J, Ye C (2008) An improved HPLC method for simultaneous determination of phenolic compounds, purine alkaloids and theanine in Camellia species. J Food Compos Anal 21:559-563. https://doi.org/10.1016/j.jfca.2008.05.002

14. Yin X-L, Wu H-L, Gu H-W, Zhang X-H, Sun Y-M, Hu Y et al (2014) Chemometrics-enhanced high performance liquid chromatography-diode array detection strategy for simultaneous determination of eight co-eluted compounds in ten kinds of Chinese teas using second-order calibration method based on alternating trilinear decomposition algorithm. J Chromatogr A 1364:151-162. https://doi.org/10.1016/j.chroma.2014.08.068

15. Azevedo RSA, Teixeira BS, Sauthier MCdS, Santana MVA, dos Santos WNL, Santana DdA (2019) Multivariate analysis of the composition of bioactive in tea of the species Camellia sinensis. Food Chem 273:39-44. https://doi.org/10.1016/j.foodchem. 2018.04.030

16. Bonoli M, Colabufalo P, Pelillo M, Gallina Toschi T, Lercker G (2003) Fast determination of catechins and xanthines in tea beverages by micellar electrokinetic chromatography. J Agric Food Chem 51:1141-1147. https://doi.org/10.1021/jf020907b

17. Hsiao H-Y, Chen RLC, Cheng T-J (2010) Determination of tea fermentation degree by a rapid micellar electrokinetic chromatography. Food Chem 120:632-636. https://doi.org/10.1016/j.foodc hem.2009.10.048

18. Vochyanova B, Opekar F, Tuma $P$ (2014) Simultaneous and rapid determination of caffeine and taurine in energy drinks by MEKC in a short capillary with dual contactless conductivity/photometry detection. Electrophoresis 35:1660-1665. https://doi.org/ 10.1002/elps.201300480

19. Marti R, Valcarcel M, Herrero-Martinez JM, Cebolla-Cornejo J, Rosello S (2017) Simultaneous determination of main phenolic acids and flavonoids in tomato by micellar electrokinetic 
capillary electrophoresis. Food Chem 221:439-446. https://doi. org/10.1016/j.foodchem.2016.10.105

20. Parveen S, Siyal AN, Memon N, Memon SQ, Khuhawar MY (2015) Extraction and determination of phenolic acids and vitamin $B$ of sieved and unsieved wheat grain by MEKC. J Liq Chromatogr Relat Technol 38:143-152. https://doi.org/10.1080/10826076. 2014.896812

21. Hancu G, Simon B, Rusu A, Mircia E, Gyéresi A (2013) Principles of micellar electrokinetic capillary chromatography applied in pharmaceutical analysis. Adv Pharm Bull 3:1-8. https://doi.org/ 10.5681/apb.2013.001

22. Deeb SE, Iriban MA, Gust R (2011) MEKC as a powerful growing analytical technique. Electrophoresis 32:166-183. https://doi. org/10.1002/elps.201000398

23. Billiot E, Billiot F, Warner IM (2008) Optimization of 12 chiral analytes with 8 polymeric surfactants. J Chromatogr Sci 46:757-763. https://doi.org/10.1093/chromsci/46.9.757

24. Schmitt-Kopplin P (2008) Capillary electrophoresis method and protocols. Humana Press, NJ

25. Obma A, Hemwech P, Phoolpho S, Bumrungpuech R, Wirasate $S$, Kaophong $S$ et al (revised work, 2021) Silica nanolayer coated capillary by hydrothermal sol-gel process for amines separation and detection of tyramine in food products

26. Liu X, Sun S, Nie R, Ma J, Qu Q, Yang L (2018) Highly uniform porous silica layer open-tubular capillary columns produced via in-situ biphasic sol-gel processing for open-tubular capillary electrochromatography. J Chromatogr A 1538:86-93. https:// doi.org/10.1016/j.chroma.2018.01.024

27. Liu X, Zhu X, Camara MA, Qu Q, Shan Y, Yang L (2019) Surface modification with highly-homogeneous porous silica layer for enzyme immobilization in capillary enzyme microreactors. Talanta 197:539-547. https://doi.org/10.1016/j.talanta.2019.01.080

28. Liu X, Azhar I, Khan H, Qu Q, Tian M, Yang L (2020) Capillary electrophoresis-immobilized enzyme microreactors for acetylcholinesterase assay with surface modification by highlyhomogeneous microporous layer. J Chromatogr A 1609:460454. https://doi.org/10.1016/j.chroma.2019.460454

29. Lin $\mathrm{Y}-\mathrm{H}$, Huang $\mathrm{H}-\mathrm{C}, \mathrm{Hsu} \mathrm{W}-\mathrm{L}$ (2015) Application of capillary electrophoresis with electrokinetic supercharging and sweeping for the on-line preconcentration of phenolic acids. Anal Bioanal Chem 407:7093-7100. https://doi.org/10.1007/ s00216-015-8869-x

30. Wang W, Zhou F, Zhao L, Zhang J-R, Zhu J-J (2007) Measurement of electroosmotic flow in capillary and microchip electrophoresis. J Chromatogr A 1170:1-8. https://doi.org/10.1016/j.chroma. 2007.08.083

31. U.S. Food and Drug Administration Foods Program (2019). Guidelines for the validation of chemical methods in food, feed, cosmetics, and veterinary products, 3rd edition [online]. https:// www.fda.gov/media/121751/download. Accessed 13 September 2020.

32. Miller JN, Miller JC (2010) Calibration methods: regression and correlation. In: Statistics and chemometrics for analytical chemistry, 6th edn. Pearson, Prentice Hall, pp 124-126

33. Christian GD, Dasgupta PK, Schug KA (2014) Chapter 3 statistics and data handling in analytical chemistry. In: Gayle A, Bull K (eds) Analytical chemistry, 7th edn. Wiley, Hoboken, pp 105-106

Publisher's Note Springer Nature remains neutral with regard to jurisdictional claims in published maps and institutional affiliations. 